\title{
The Impact of the Implementation the Concept of Knowledge Management on Security Crisis Management
}

Zaki AM Abuzyead* and Sherifa Fouad Sherif

Department of Public Administration, Cairo University, Palestinian territories, Egypt

\begin{abstract}
This study aimed to identify the impact of applying the concept of knowledge management on security crisis management in the joint operations rooms of the Palestinian security forces in the West Bank governorates. In order to achieve the objectives of the study, the researcher used the analytical descriptive method, and the questionnaire was used as a tool for collecting the necessary data from the study society, which represents all the officers in the joint operations room, which number (352) officers. The results of the study showed significant effect with statistically significant at the level of significance $(\alpha \leq 0.05)$ for knowledge management processes (knowledge diagnosis, knowledge generation, knowledge storage, knowledge distribution, and knowledge immplementation) on stages of security crises management in the joint operations rooms of the Palestinian security services.
\end{abstract}

Keywords: Knowledge management; Security crisis management; Security sector

\section{Introduction}

Today, the world is witness to a number of changes, changes and developments that affect various aspects of life, which are not expected to stand at a certain level. In light of these consective changes and developments in security events, the Palestinian security establishment faces many challenges in current stages, being it does not live in isolation from the world, it affects and is influenced by the variables around it, it is exposed to many security crises in the exercise of its activities, making them live almost constantly to security crises, which necessitates a change in their systems and administrative methods to suit the developments of the age and its challenges.

In order to face these challenges, knowledge management is one of the most important methods and systems used to address these challenges as one of the most modern administrative concepts in our Arab societies, which is based on a set of ideas and guiding principles and philosophies that any institution management can take as an input to dealing with various security challenges and crises unexpected and unpredictable, which enables the institution to exploit its resources of data and information in order to increase efficiency and effectiveness. Therefore, the practice of knowledge management in its various operations and functions is a core and essential requirement to increase the security institution's ability to improve security operations and procedures, so it is no longer theoretical knowledge based on attracting and presenting information and knowledge and provide them only abstract it is based on creating a knowledge-based work environment that facilitates the creation, transfer and sharing of knowledge, maximizing the information available in the organization and the individual experiences inherent in the minds of its employees, leading to efficient and effective security crisis management.

Therefore, this study comes with complete integrated vision to measure the impact of implementation the concept of knowledge management on the management of security crises in the joint operations rooms of the Palestinian security forces, this is because knowledge management is an important element in the effectiveness of the security institutions when faced with various crises, and we hope that this study will be a step not the first and the last in this field.

\section{Problem of the Study}

The issues of knowledge management and security crisis management have received much attention from many researchers and specialists in this field. However, there is a gap in the literature and applied studies regarding the impact of the implementation of knowledge management on crisis management, especially in the field of security. Limits of theoretical analysis, where the study of this effect remained within the limits of theoretical analysis, and it has not been tested through research and field studies in our Arab societies, the main problem of the study lies in the lack of awareness of the impact of knowledge management on the management of security crises in the joint operations rooms of the Palestinian security forces specifically, which is considered the core problem of our study, and the problem of the study represent the low level of awareness and perception of the senior leadership in the security establishment the concept and importance of knowledge management, and the processes that go through, and how to apply, due to many of the constraints faced by that institution, which prevent access to a level of intellectual and advanced knowledge in managing security crises efficiently and effectively, that making it more necessary to employ knowledge management in managing security crisis. Hence, the problem of the study can be framed in the following question:

- What is the reality of Knowledge Management (KM) implementation? And what its impact on the management of security crises from the point of view of officers working in the joint operating rooms of the Palestinian security forces in the West Bank governorates?

\section{Objectives of the Study}

In order to grasp the dimensions of the study problem, this study seeking and aims to achieve the following objectives:

- To identify the reality of the implementation knowledge

*Corresponding author: Zaki AM Abuzyead, Department of Public Administration Cairo University, Palestinian territories, Egypt, Tel: 00970598770077; E-mail: zaki_abuzyeada@hotmail.com

Received May 30, 2017; Accepted June 22, 2017; Published June 30, 2017

Citation: Abuzyead ZAM, Sherif SF (2017) The Impact of the Implementation the Concept of Knowledge Management on Security Crisis Management. Review Pub Administration Manag 5: 216. doi:10.4172/2315-7844.1000216

Copyright: ( 2017 Abuzyead ZAM, et al. This is an open-access article distributed under the terms of the Creative Commons Attribution License, which permits unrestricted use, distribution, and reproduction in any medium, provided the original author and source are credited. 
management in the joint operating rooms of the security forces under study, from the point of view of the respondents.

- Identify the reality of security crisis management in the joint operating rooms of the security services under study, from the point of view of the respondents.

- Identify impact range of implementation the concept of knowledge management on security crisis management in joint operation rooms of the Palestinian security forces.

- To present a set of recommendations based on the findings of this study to the decision makers in the Palestinian security establishment, which contribute in enhancing the impact of the implementation knowledge management on managing security crises in a manner. Commensurate and compatible with the reality of the joint operation rooms of the Palestinian security forces under study.

\section{The importance of the study}

This study derives its importance from the following:

- This study is one of the first studies on the level of the Arab environment in general, and the Palestinian environment in particular, within the limits of the researcher's knowledge, which deals with the impact of the implementation of knowledge management on security crisis management in the joint operation rooms of the Palestinian security forces. It is therefore hoped that this study will provide a new scientific addition that may contribute to enriching the Arab library.

- The importance of this study is also highlighted by the importance of the Palestinian security establishment, specifically the joint operation rooms of the Palestinian security forces which is considered the first to deal with the various security crises, because of the different roles it has in their management by providing information to decision makers from the field and how to coordinate with other concerned government agencies, avoid security crises before they occur, and achieve stability, preservation, and protection the vital interests of the state.

\section{Theoretical Framework and Previous Studies}

\section{Theoretical framework}

\section{Knowledge management concept}

The definitions of knowledge management have multiplied by the number of researchers on this subject, this is not strange, since we are dealing with a philosophy and a culture of management with divergent opinions and different attitudes and intellectual attitudes. Hence, there is no agreement on the possibility of introducing a unified and specific definition of the concept of knowledge management so far, for the purpose of this study, and in line with its objectives, we will review the most important definitions to stand on the impact of implementation the concept of knowledge management on managing security crises as a qmodern entry into the development of knowledge management.

One of the researchers defined knowledge management as "an administrative activity that develops, stores, distributes, transfers, implements and uses knowledge to achieve organizational objectives, decision-making and problem solving in order to achieve excellence and efficiency in the Organization" [1], Another is defined as "the group of processes developed in the organization to generate, store, transfer and apply knowledge, which increases the organization's ability to learn from its external and internal environment for decision-making" [2] as defined by another as "an attempt to improve or maximize the use of knowledge in the organization or system, Knowledge and valuable value Derived from the sharing and use of this knowledge throughout the Organization"[3].
In the same context, one of the researchers defined the management of security knowledge as» this organized effort consciously directed by any security administrative or department or any of the security authorities in order to work on compilation different types of information, classification, and storage for use and benefits fromit in the security field, This should be done in such a way as to facilitate the circulation and sharing of such information among the various security cadres in the departments, administrations, and relevant branches. Leading to rational decision making and improved security performance in order to achieve high quality security performance" [4]. Security knowledge management is also defined as: "A means to simplify and improve the process of exchange data, information, and experiences; and distribution, publishing, analysis, understanding and circulation in the security establishment, so knowledge management as an administrative method interacts with the components of knowledge which are available in the security forces, are the means of managing activities that are characterized by intense collective knowledge "[5].

Based on the above, and until this study, and in accordance with the nature and objectives of the study and its society represented in the security sector, knowledge management can be defined as: a set of integrated systemic processes that help the joint operations rooms of the security forces to diagnose, generate, store, and distribute knowledge, to increase the efficiency of officers working in knowledge to manage security crises efficiently and effectively in light of age changes.

As definitions concept of knowledge management have also been varied, knowledge management processes also vary with the various visions and models of their management, one researcher identified knowledge management processes in three processes: knowledge gathering, knowledge storage, knowledge publishing [6] Others define it by four processes: acquisition of knowledge, application of knowledge, protection of knowledge, transformation of knowledge [7] In the same Vol, others determined knowledge by gathering, organizing, use, and protection of knowledge [8,9], and theres who are divided Knowledge management processes into five processes: Capture knowledge, store knowledge, share knowledge, apply knowledge, generate knowledge [10]. And others restrict it to knowledge formation, knowledge storage, knowledge processing, knowledge sharing, and use of knowledge [11]. On the other side, a number of researchers identified knowledge management processes in six processes: knowledge diagnosis, knowledge acquisition, knowledge generation, knowledge storage, knowledge development and distribution, knowledge application [12-15].

In this part, the researcher considers that it is not feasible to delve into the reasons for the different names and the number of operations and their arrangement. Rather, the focus of this study will be on the processes that we consider to be the most comprehensive and used in the practical reality of the security sector. Based on the literature and studies related to this subject some processes have been chosen for their relevance to the nature of the study, its objectives and its community, represented by the joint operations rooms. These processes are in the order of: "knowledge diagnosis, knowledge generation, knowledge storage, knowledge distribution, and implementationof knowledge. "These processes will be reviewed as independent variables. In order to stand on the level of knowledge management implementation in the joint operating rooms of the security forces.

\section{Knowledge diagnosis}

Knowledge diagnosis is one of the most important processes in any knowledge management program, in light of this diagnosis, other operational policies and programs are assigned and developed because 
the results of the diagnostic process know the type of knowledge available, and compare it with what is required to identify the gap [16], which define for us critical knowledge inside and outside the organization and then determine their place and the cognitive gap [17], that process involves the collection and analysis of knowledge, drawing conclusions for future planning, and may aim to identify the causes of specific problems, provide solutions and improve the effectiveness of the organization [18].

\section{Knowledge generating}

In the second stage after the process of knowledge diagnosis comes the process of knowledgegenerating, which involves many processes of capturing, buying, inventing, discovering, absorbing, getting or acquiringit [19], and its a process of creating, deriving and forming knowledge within the establishment and reaching new knowledge [20], i.e., developing a new knowledge of data and information or previous knowledge [21], as that the process of generating knowledge represents the ability of the establishment to form a new knowledge base as a result of the interaction between the implicit knowledge of the employees and the explicit knowledge (formal) that represents the organization's balance of expertise, transactions, decisions and policies [22].

\section{Knowledge storage}

The security establishment may be make a great effort to generate knowledge, but it may be vulnerable to losing it either by forgetting or by obstructing access to it. Hence, storing and retrieving knowledge when needed is one of the important and fundamental operation for the security establishment. These are those operations that include keep, sustainability, search, access, retrieval, and warehousing [23], so knowledge storage is the bridge between knowledge capture and retrieval [24], which is considered the organizational memory for the establishment, which Represented by the ways in which knowledge of the past influence and its events current organizational events [25]; this memory serves as the repository in which knowledge is developed for future use [26].

\section{Knowledge distribution}

In the fourth stage after the process of knowledge storage comes the process of knowledge distribution, which represents and involves many of the processes represented by transfer, sharing, diffusion, moving, exchange, transformation, and flow [27], and means by knowledge distribution process involves transferring and providing expertise and knowledge to handels and acquire amongemployee [28], which is the transmission of the right knowledge to the people who need it in a timely manner in order to carry out essential tasks [29], through the creation of good means of communication and a culture that encourages their dissemination within the boundaries of the establishment; which suggest ensuring that the appropriate knowledge is available to the person in question at the appropriate time, and that it reaches as many persons as possible working at the establishment [30].

\section{Knowledge implementation}

The aim and purpose from knowledge management is to apply the knowledge available to the organization. This implementation is the most notable of its operations. This process refers to the terms of use, reuse, utilization, and applying [31], and men by applying knowledge making the activities of the organization are more appropriate to use and more relevant to the tasks it performs [32]; which it is a mechanism that involves assimilating knowledge and translating it into actionable processes on the reality [33]. Therefore, the implementation of knowledge is the goal of knowledge management. It means knowledge investment. So, capturing, access, storage participation and distribution of knowledge is not enough, the important thing is to transform knowledge into implementation, knowledge that is not reflected in implementation or executing remains a lost cost, and the success of any institution in knowledge management programs depends on the amount of knowledge implemented relatively to what is available [34].

\section{The Concept of Security Crisis Management}

Researchers and writers have also differed in the definition of crisis management according to the nature of the crisis and its impact, and the necessary treatment methods that vary depending on the nature of the crisis and the forces latent behind it. Therefore, crisis management has been defined by multiple definitions, such as "it is a distinct management process because it is subject to a sudden event and needs decisive and rapid actions that are consistent with the developments of the crisis. Thus, crisis management has the lead in leading, influencing and directing events according requirements" [35], and another defines it as "a set of factors designed to combat crises and mitigate actual harm, namely to seek to prevent or mitigate the negative consequences of the crisis, thereby protecting the organization and stakeholders from harm" [36].

With regard tothe concept of the security crisis management is not very different from the general concept of crisis management only in giving the security status on the crisis management and results, and use force or show the intention of using it, which is an essential part of the preparedness process to cope with the security crisis or actuallyfacing it [37], which one of the researchershas been defined security crisis management as "a set of procedures and mechanisms that rely on knowledge and science are followed by who on in charge of management crisis (crisis management team) in the stage of pre-crisis occurrence (prevention), or as they occur in order to minimize their effects, or after they occur to removeImplications " [38], and defined by another as" all theoretical tactical and practical operational efforts led by the security agencies concerned about dealing with crises that would breach national security in his complete concept "[39]

Based on the above, for the purposes of this study, and in consistency with the nature and objectives of the study and study society represented by security sector, we can defined security crisis management as: "an integrated complete dynamic process of security procedures and operations carried out by joint operations rooms of the security forces represented by (discovery of early warning signals, prepare and prevention for the crisis, confrontation and containment of damage, restoration of activity, strategic learning), to deal with security crises efficiently and effectively in the pre-crisis stage, during and after they occur; In order to prevent and contain the security crisis and reduce their effects, and restore the situation to normal, and then draw lessons and results to avoid its occurrence in the future".

In addition to the various definitions of the concept of security crisis management, the stages of crisis management also vary, Many researchers differed on defining the stages of crisis management and census in accordance with their different orientations and the variety of their specialties and their research and scientific purposes, one of researchers identified three stages of crisis management: crisis prevention, crisis response, rebalancing [40], there are those who divide the stages of crisis management into four stages: the readiness, response, recovery, learning [41], while others constrain it in stages of prevention, outbreak crisis, treatment and evaluation, reconstruction [42]. There are also those who divide the stages of crisis management into five stages: symptom phase, prevention and preparedness, containment, rebalancing of activity, learning [43]. Others identified by the stage 
of detection of early warning signals, preparedness and prevention, containment and reduction of damage, recovery, learning [44-46], there are who identified it in six stages: discovery stagee, preparedness and prevention, containment, confrontation, regain control, learning [47].

Based on the literatures and studies related to this subject, some stages of crisis management, which work in a sequential and integrated manner, have been selected for their relevance to the nature of the study and its objectives and society represented by the security sector. These stages are: "detection of early warning signals, preparedness and prevention. Confrontation and containment of damages, restoring activity, Strategic Learning, "which will be reviewed as dependent variables, to determine levels of implementation in the joint operating rooms of the security forces.

\section{Detection of early warning signals stage}

This stage refers to the pre-actual phase of the security crisis. Usually, the security crisis sends a long chain of early warning signals, or symptoms that predict its occurrence [48]. If these signals are not given enough attention, the crisis is very likely to occur, the means detection of signals of early warning process of monitoring, recording, and analysis of signals that predict the near crisis [49], they are tools that give signs of the potential for a crisis occurrence, which can identify the dimensions of a situation before the deterioration and turn it into a real crisis [50].

\section{Preparedness and prevention stage}

Preparedness and prevention stage considered as an ongoing function from main security crisis management functions to ensure that the concerned security agencies are on a standstill and are ready to deal with crises at some point in their development [51]. Represented by a set of elements that reflect the extent to which the addministrative has made preparations for crisis prevention, making preparations for predictable crises and planning for unavoidable situations, in order to control the crisis and reduce its severity and effects if it occurs despite the efforts spent to prevent it from happening [52].

\section{Confrontation and containment of damages stage}

If the security crisis declares itself either as a sudden explosion or a gradual escalation leading to a worsening of the security situation, it is an explicit declaration that the failure of preventive efforts to end the crisis, and here requires the implementation of direct confrontation operations represented by all efforts directed to control the situation and ending the crises with minimum losses [53]. This stage comes as a result of the failure to take the appropriate measures in a timely manner, and through this stage to limitation the damage caused by the crisis [54], it is a stage of practical implementation of pre-set measures to deal with the crisis [55], so prepared preventive plans are reviewed and modified in light of the actual situation of the crisis and the magnitude of the resulting impacts [56]. As much effort and good planning as in previous stages, mostly the success of managing the security crisis is often determined in the theater of confrontation [57].

\section{Recovery stage}

The stage that comes after the stage of confrontation and the containment of the damages directly, and the administration has defined the dimensions of the crisis and its causes, enabling them to provide some realistic solutions, starting to restore balance and return to the situation that existed before the crisis [58] and this stage includes gather enough information about the crisis and its consequences, mitigate its damages, identify the necessary needs for normalcy [59].

\section{Strategic learning stage}

Which is the stage after the disappearance of the security crisis, but it is a continuous stage of continuous learning and reassessment to improve what has been achieved in the past [60], where after the security crisis must work to review the crisis and the reasons of occurrence and the method followed to face and how to overcome the crisis. To find out the mistakes that have been made to try to repair them and to ensure that they do not recur in the future to raise the level of performance within the various security forces [61].

\section{Previous Studies}

The previous studies form a basic tribute from tributary of theoretical and practical knowledge. Based on this reality, the researcher undertook a comprehensive survey of scientific journals in search of scientific, theoretical, or field studies related to the subject of this study. The following is a presentation a number of Arabic and foreign studies related to the subject of the study taking into account the current study requirements, the study can be divided into the following axes:

\section{First: Studies concerned with the study of knowledge man-} agement axis

Al-Kasasbh [62] conducted a study aimed at measuring the impact of knowledge management in developing a culture of excellence in commercial banks operating in Tabuk City, the study found that the level of assessment of the employees in the banks to the dimensions of knowledge management was high, the study also showed a statistically significant impact on all dimensions of knowledge management in the culture of excellence in the commercial banks operating in the city of Tabuk [62].

Al- Enezi [63] conducted a study aimed at identifying the reality of knowledge management in the leadership of the border guards in Tabuk region and its impact on the positive organizational culture prevailing in it, the study found many conclusions and the most important was: the belief of the workers in the leadership of Border Guard in the Tabuk region and strongly that knowledge management adds value to the results of border guards, and that there is an effective impact of knowledge management in creating and development of organizational culture in the Border Guard leadership in the Tabuk region [63]

Al-Zogby, Al-Zaidi [64] conducted a study to determine the impact of management information systems on knowledge management processes from the point of view of employees in Jordanian ministries. The study found that respondents' attitudes towards the dimensions of management information systems and knowledge management processes comes with a high level, the study also showed a statistically significant effect at the level of significance $(\alpha \leq 0.05)$ for the dimensions of Management Information Systems (MIS) in knowledge management processes [64].

Kasim [65] also conducted a study to demonstrate the important role of knowledge management practices in improving the performance and efficiency of Malaysian publicsector institutions. The study concluded that the practice of knowledge management involves three main dimensions: knowledge acquisition, knowledge dissemination and knowledge response. The study confirmed a positive relationship between knowledge management practices and efficiency of performance in Malaysian public sector institutions [65].

Darwish [66] conducted a study aimed to identifying and implementing knowledge management in the field of security. One of the most important findings of the study was that the subject of 
knowledge management is modern and developed rapidly. The study also pointed to the extent appropriateness of the issue of knowledge management for security institutions, since many aspects of security work depend on implicit or experiential knowledge [66].

\section{Second: Studies that dealt with the study of crisis management axis}

Al-Otaibi [67] conducted a study aimed at identifying the role of the Kuwaiti National Guard in the prevention of security crises and its strategies in confronting them. The study concluded that the most important strategies that can be followed in the face of security crises are simplifying, facilitating security procedures, and subjecting the crisis to the scientific methodology [67].

And Pol conducted [68] a study to determine the preparedness of public hospitals in Cuba for crises, the most important findings of the study were that readiness levels were low and there was insufficient preparedness by organizations to prevent crises due to fragmentation of preventive planning, and limited understanding of humanitarian and social aspects [68].

And Unlu conducted a study [69] with a view to clarifying the extent evolution of the crisis and disaster management systems of the Government and Turkish regime, the study found that the Turkish regime has a large coordination problem, as there is no clear mechanism for cooperation and coordination between institutions operating in crisis and disaster management, and not to benefit from past experiences of crises and disasters that occurred in earlier times [69].

Abu al-Nasr [70] also conducted a study aimed to identifying the concept of security crisis management. One of the most important findings of the study was that the crisis expresses an undesirable situation and is a clear threat to one of the values and interests. Resulting in a deterioration of events that are out of control, the study also pointed to the importance of adopting the principles and foundations of crisis management, and negotiating as a method of managing and ending security crises [70].

The AL-Araji and Zaher [71] conducted a study with the aim of identifying the readiness of the Civil Defense Directorate in Jordan to face and deal with crises. The study reached several results, the most important of which are: the clarity of the stages of crisis management among the supervisors. The study also showed the effect of both human factors and geographical and technical divergence on in the level of readiness of the Jordanian Civil Defense Directorate [71].

\section{Third: Studies that studied the impact and relationship between the implementation of knowledge management and crisis management axis}

Mahmoud [72] conducted a study to identify the nature of the relationship and the impact of knowledge transfer in the future of crisis management in Iraqi banks, the study found a varying correlation relationship degrees between knowledge transfers and the future of crisis management, the study also pointed out that one of the most important variables is the transfer of knowledge crisis management is the use of efficient communication [72].

Zhiyang [73] conducted a study aimed to identifying the framework of knowledge management systems in crisis management in tourism field. The study concluded that the acquisition, creation and storage of knowledge are most relevant to the stages of crisis management [73]

Tsong and Cheng [74] conducted a study to identify knowledge transfer channels during organizational crises. The study found that multiple knowledge transfer channels were used and that these channels had an important positive impact on organizational performance when dealing with the crisis [74].

Wang [52] also conducted a study to understand the role of knowledge management in raising organizational performance during crises in the Natural Gas Company in China. The study reached several conclusions, the most important of which is: that knowledge management plays an important role in crisis management, and that organizations have knowledge needs that require different knowledge management strategies at each stage of crisis management stages, and the results of the study indicate that crises that threaten organizations can be avoided and reduced if identified necessary knowledge in advance [75].

Wang and Belardo [76] Conducted a study aimed to identifying the extent to which knowledge management in crisis management can affect two energy companies in Taiwan, the study found that any organization needs to employ different strategies of knowledge at different stages of crisis management in the sample study companies, in order to avoid crises and meet their different needs. the study also noted that there are important relationships between the strategies of knowledge and stages of crisis management and its characteristics, knowledge management has a positive impact on crisis management [76].

Zhihong and Wang [77] conducted a study to identify how to deal with the crisis management system of knowledge-driven projects according to the life cycle analysis of the crisis, the study concluded that knowledge management is important in crisis management and a good crisis management approach should be found that helps to promote and improve the efficiency and effectiveness of crisis management through the knowledge required [77].

Based on the foregoing: we note from the presentation of the various previous studies on the subject at the Arab and foreign levels, that this study is complementary to the results of these studies. The previous studies that dealt with the impact of the implementation of knowledge management on crisis management are still very limited in the foreign environment, especially in security, and did not address some of the dimensions in this study, but on the level of the Arab environment in general, and the Palestinian environment in particular, studies are almost non-existent in this area, so it is hoped that the current study adds a modest brick at the theoretical and practical levels.

\section{Study Model}

Based on previous studies, and consistent with the objectives of the study and its community of joint operating rooms of the Palestinian security forces, a model has been formulated that includes knowledge management as an independent variable and security crisis management as a dependent variable.

The following Figure 1 is a Clarification of this model:

\section{Study Hypotheses}

Based on the variables and dimensions presented in the study model, and based on the problem of the study and its objectives, a number of hypotheses were formulated for the purpose of measuring the effect of the independent variables in the dependent variables, here are the hypotheses drafted as null hypothesis (Ho):-

\section{The main hypothesis}

There is no significant effect with statistical significance at the level of indication $(\alpha \leq 0.05)$ for knowledge management process 


\begin{tabular}{|c|c|c|}
\hline \multicolumn{1}{|c|}{$\begin{array}{c}\text { Independent variable } \\
\text { (knowledge management) }\end{array}$} & \multicolumn{1}{c|}{$\begin{array}{c}\text { The dependent variable } \\
\text { (Security Crisis Management) }\end{array}$} \\
\hline knowledge diagnosis & Detection of alarm signals \\
\hline Knowledge generation & Preparedness and prevention \\
\hline Knowledge storage & Confrontation and containment of \\
\hline Knowledge implementation & Strages \\
\hline
\end{tabular}

Source: Prepared by the researcher

Figure 1: Study mode.

(knowledge diagnosis, knowledge generation, knowledge storage, knowledge distribution, and knowledge implementation) on the stages of managing security crises in Joint operating rooms of the Palestinian security forces.

\section{It emanates from the main hypothesis the following sub- hypothesis}

- First Sub-hypothesis: There is no significant effect with statistical significance at the level of indication $(\alpha \leq 0.05)$ for knowledge management process (knowledge diagnosis, knowledge generation, knowledge storage, knowledge distribution, and knowledge implementation) on the stage ofearly detection of early warning signals as a stage of security crisis management.

- Second Sub-hypothesis: There is no significant effect with statistical significance at the level of indication $(\alpha \leq 0.05)$ for knowledge management process (knowledge diagnosis, knowledge generation, knowledge storage, knowledge distribution, and knowledge implementation) on the stage of preparedness and prevention as a stage of security crisis management.

- Third Sub-hypothesis: There is no significant effect with statistical significance at the level of indication $(\alpha \leq 0.05)$ for knowledge management process (knowledge diagnosis, knowledge generation, knowledge storage, knowledge distribution, and knowledge implementation) on the stage of confrontation and containment of damages as a stage of security crisis management.

- Fourth Sub-hypothesis: There is no significant effect with statistical significance at the level of indication $(\alpha \leq 0.05)$ for knowledge management process (knowledge diagnosis, knowledge generation, knowledge storage, knowledge distribution, and knowledge implementation) on the stage of restoring activity as a stage of security crisis management.

- Fifth Sub-hypothesis: There is no significant effect with statistical significance at the level of indication $(\alpha \leq 0.05)$ for knowledge management process (knowledge diagnosis, knowledge generation, knowledge storage, knowledge distribution, and knowledge implementation) on the stages of strategic learning phase as a stage of security crisis management.

\section{Methodology of the Study}

\section{Society and study sample}

The study population consists of all the officers working in the joint operations rooms of the Palestinian security forces in the West
Bank governorates, who are on their job during the year 2016, and their number is (352) respondents [78]. The reason for determining this category (officers of the operating rooms) as researcher thought that this category of workers is better able to understand the nature and dimensions of the variables and deal with them scientifically, as they constitute a team capable of dealing with security crises by virtue of their service, responsibilities, and knowledge to address such crises. Because of the small size of the study population, a comprehensive (survey) method was used for the entire study population. The researcher distributed (352) questionnaires, which included all the study population, and retrieved (309) responses with a retrieval rate of $(87.8 \%)$, Five questionnaires were excluded because they were not valid for statistical analysis, the number of questionnaires valid for the analysis (304) was determined to form (98.4\%) from the retrieved questionnaires and (86.4\%) from the population and sample of the study which is acceptable percentage for the purposes of scientific research.

\section{Data Collection Methods}

Based on the nature of the study and its objectives, the researcher adopted the analytical descriptive design for its relevance to the study, and relied on two main sources to obtain the necessary data and information:

- Secondary sources: Represented by the use of references and resources available in libraries, in order to build the theoretical framework of this study, including: scientific books, specialized periodicals, university thesis, and websites.

- Primary Sources: To address the analytical aspects of the subject of the study, the researcher sought to collect the data from the study community by means of the questionnaire prepared for this purpose. The questionnaire consisted of three main parts as follows:

- Part one: Includes demographic variables related to the personal and functional data of the study population (gender, military rank, age, years of experience, qualification).

- Part two: This section includes a (37) section aimed to measuring the level implementation of knowledge management in the joint operating rooms of the Palestinian security forces (as independent variables) and these are: knowledge diagnosis (paragraphs 1-7), knowledge generation (paragraphs 8-14), knowledge storage (paragraphs 15-21), knowledge distribution (paragraphs 22-29), knowledge implementation (paragraphs 30-37).

- Part three: Consists of (33) paragraphs from which through them was evaluate the reality of managing the security crises in the joint operation rooms of the Palestinian security forces (as dependent 
Citation: Abuzyead ZAM, Sherif SF (2017) The Impact of the Implementation the Concept of Knowledge Management on Security Crisis Management. Review Pub Administration Manag 5: 216. doi:10.4172/2315-7844.1000216

Page 7 of 15

variables) which: detection of early warning signals Stage (paragraphs 1-7), preparedness and prevention stage (paragraphs 8-15), confrontation and containment of damages stage (paragraphs 16-22), recovery stage (paragraphs 23-28). Strategic learning stage (paragraphs 29-33). The study adopted a five-point Likert scale for all dimensions of the study, which ranging from strongly agreed with values (5) degrees and not strongly agreed values one degree.

\section{Validation and Stability of the Tool}

To verify the true (validity) of the questionnaire used in the study, it was presented to (15) arbitrators with the accumulated scientific and practical experience from security leaders, academics specialized in this field and those working in the Palestinian universities. In order to assure from the ascertain veracity of the paragraphs of the questionnaire, their clarity, the integrity of their language and content, and their ability to measure the variables of the study, in addition, the questionnaire was presented to a sample of (15) respondents from the sample, in order to ensure and understand the degree of understanding of the questionnaire paragraphs, their degree of clarity and ease and in light of their opinions and suggestions. The researcher deleted and modified some of the paragraphs, and rephrased some of them to become the closest understanding and to achieve the objectives of the study, also conducted a test of the degree of stability of performance "Reliability Analysis", by calculating the value of Cronbach-Alpha "Cronbach's-Alpha" for the study variables, as shown in Table 1 below:

It nots from the results of Table 1 that the value of the Cronbach alpha coefficient for all performance paragraphs reached $(\alpha=95.5 \%)$, which is higher than the minimum acceptable limit (70\%) for such studies and research $[79,80]$ The study is highly stable and acceptable for the purpose of conducting the study. To ensure that the measuring instrument used in the study obtained a high degree of stability and acceptable for the purposes of conducting the study.

\section{Statistical Methods Used in the Study}

To achieve the objectives of the study and to test the validity of its hypotheses, descriptive and analytical statistical methods were used, using the Statistical Package for Social Sciences (SPSS: 21) as follows:

- Descriptive statistics methods to describe the characteristics of the study society, based on the frequency, the arithmetic mean, the standard deviation, the importance ratios for describing the variables of the study, and their order according to their relative importance. From this point, the responses of the sample survey respondents to the questionnaire questions were categorized to categories according to the arithmetic mean and the relative importance of the answer, according to the five-dimensional Likert $\mathrm{f}$ scale used in the study axes as follows:

The length of the class $=($ the upper limit of the alternative - the minimum limit of the alternative)/the number of levels

$$
=(5-1) / 5=4 / 5=0.8
$$

After that this value is added to the lowest value in the fivedimensional Likert scale which is the right one. Table 2 shows the degrees or levels of measurement of the descriptive results according to the following specification.

- Making Stability analysis of the (Cronbach's Alpha Reliability Analysis), for internal consistency, to determine the stability coefficient of the instrument used to measure the variables.

- Examine T-Test One Simple test to determine the reality of knowledge management implementation and the level of crisis

\begin{tabular}{|c|c|}
\hline Alpha value & Variables \\
\hline $96.1 \%$ & Independent variable (knowledge management processes). \\
\hline $95.2 \%$ & The dependent variable (stages of security crisis management). \\
\hline $95.5 \%$ & All variables (tool as a whole) are combined. \\
\hline
\end{tabular}

Table 1: The value of the Cronbach alpha coefficient for the study variable.

\begin{tabular}{|c|c|c|}
\hline \multirow{2}{*}{ Degree of approval } & \multicolumn{2}{|c|}{ The range } \\
\cline { 2 - 3 } & Relatively importance & Arithmetic mean \\
\hline Very high & from $84 \%$ to $100 \%$ & $4.20-5$ \\
\hline High & from $68 \%$ to less than $84 \%$ & 3.40 -less than 4.20 \\
\hline Medium & from $52 \%$ to less than $68 \%$ & 2.60 -less than 3.40 \\
\hline Low & from $36 \%$ to less than $52 \%$ & 1.80 -less than 2.60 \\
\hline Very low & $1 \%$ to less than $36 \%$ & Less than 1.80 \\
\hline
\end{tabular}

Table 2: Degrees or levels of measurement of the descriptive results.

\begin{tabular}{|c|c|c|}
\hline Personal and functional variables & Frequency & P.C. (\%) \\
\hline Male & 298 & $98 \%$ \\
\hline Female & 6 & $2 \%$ \\
\hline Under lieutenant & 49 & $16.1 \%$ \\
\hline First lieutenant-captain & 83 & $27.3 \%$ \\
\hline Major-Colonel & 171 & $56.3 \%$ \\
\hline Above Brigadier-general & 1 & $0.3 \%$ \\
\hline Younger than 25 years & 18 & $5.9 \%$ \\
\hline 26 years to 35 years & 92 & $30.3 \%$ \\
\hline 36 years to 45 years & 108 & $35.5 \%$ \\
\hline Older than 46 years & 86 & $28.3 \%$ \\
\hline Less than 5 years & 21 & $6.9 \%$ \\
\hline 6 years to 10 years & 34 & $11.2 \%$ \\
\hline 11 years to 15 years & 80 & $26.3 \%$ \\
\hline More than 16 years & 169 & $55.6 \%$ \\
\hline Less than diploma & 41 & $13.5 \%$ \\
\hline B.A. & 217 & $71.4 \%$ \\
\hline M.A. & 44 & $14.5 \%$ \\
\hline Ph.D. & 2 & $0.6 \%$ \\
\hline
\end{tabular}

Table 3: The personal and functional characteristics of the study sample $(\mathrm{N}=304)$.

management in the joint operating rooms of the Palestinian security forces, it was used by the researcher to ascertain the significance of the mean.

- Multiple regression analysis to test the validity of study models, and to measure the impact of the role of knowledge management implementation on security crisis management at all stages.

- Variance Inflation Factor (VIF) and tolerance test to ensure that there is no high correlation between the independent variables.

- Test the (skewness) coefficient to ensure that the data follows the normal distribution (normal distributions).

\section{Analysing Results}

\section{First: The results of the study sample's characteristics}

The following shows personal and functional variables of study sample (Table 3)

The study sample characteristics are as the following:

- Zender: (98\%) of the study sample were male and the rest were female (2\%). This indicates that female participatin in security work less than men in the joint operating rooms.

- Military rank: The majority of respondent's military rank is within the category (major-colonel) which constitute (56.3\%) of the 
Citation: Abuzyead ZAM, Sherif SF (2017) The Impact of the Implementation the Concept of Knowledge Management on Security Crisis Management. Review Pub Administration Manag 5: 216. doi:10.4172/2315-7844.1000216

Page 8 of 15

study sample, while (27.3\%) of the study sample whose military rank within the category (first lieutenant-captain), and those whose under lieutenant constitute $(16.1 \%)$ of the study sample. Only $(0.3 \%)$ are within the category (above brigadier-general). This indicates that the respondents have an experience and security knowledge, because the joint operating rooms need planning and supervision in the first place.

- Age: The majority of respondent's ages are within the category (36 years to 45 years) which constitute $(35.5 \%)$ of the study sample, followed by the age category ( 26 years to 35 years) which constitute (30.3\%), and the age category for whom are (older than 46 years) which constitute $(28.3 \%)$. This indicates that the majority of respondents have sufficient practical experience, which may have an important role in implementing knowledge management, and managing security crises efficiently.

- Years of Experience: The results show that (55.6\%) of respondents have experience (more than 16 year), (26.3\%) of respondent's experiences are within the category (11 years to 15 years), and (11.2\%) of respondent's experiences are within the category (6 years to 10 years), while only (6.9\%) have experience (equal to or less than 5 years). These results indicate that the average of years experience is relatively high, and the majority of officers who works in the joint operating rooms have good security and management experience in their field. This experience of security work enables them to create new knowledge, if they want.

- Qualification: (71.4\%) of respondents hold (B.A) degree, and (15.1\%) of the respondents hold (master or Ph. D), while (13.5\%) are less than diploma. These results show that $(86.5 \%)$ of respondents are highly qualified, which indicats that the efficiency in the joining operating rooms is available.

\section{Second: Results of analysing study variables}

One sample T-test has been used to analyze the study variables. These results are summarized as the following:

* Results of knowledge management processes' implementation of in the joint operations rooms of the The Palestinian National Security Forces (PNSF), from the point of view of respondents in (Table 4):

${ }^{*}$ When $(\alpha \leq 0.05)$, there is significance level, ${ }^{* *}$ When $(\alpha \leq 0.05)$ there isn't significance level
Data in Table 4 shows that the joining operating rooms are generally concerned with the implementation of all knowledge management processes to a high degree. The mean of all knowledge management operations reached (3.92), the interest rate reached $(78.4 \%)$ which is larger than the neutral interest rate $(60 \%)$. The calculated $(\mathrm{T})$ value is (31.24), which is larger than the tabular value (1.97). (P) value $(0.000)$, which is less than (0.05), however they were applied to varying degrees and levels. The highest level of implementing for those processes were associated with (knowledge storage, followed by knowledge distribution, then knowledge generation, and knowledge diagnosis), while the lowest level of implementing is associated with knowledge implementation. This result indicates that the joining operating rooms focus on knowledge management implementation of some processes and neglect others. However, the availability of such levels of implementation greatly helps to track of all other dimensions, and to remove obstacles that prevent the full implementation of these processes.

* Results of security crisis management's stages in the joint operations rooms of the Palestinian national security forces (Table 5):

${ }^{\star}$ When $(\alpha \leq 0.05)$, there is significance level, ${ }^{* *}$ When $(\alpha \leq 0.05)$ there isn't significance level

Depends on Data in Table 5 shows that the joining operating rooms are generally concerned with the implementation of all knowledge management processes to a high degree. The mean of all knowledge management processes reached (3.83), the interest rate reached $(76.6 \%)$ which is larger than the neutral interest rate $(60 \%)$. The calculated (T) value is (27.84), which is larger than the tabular value (1.97). (P) (0.000), which is less than (0.05). The highest level of implementing of those stages was respectively (the phase of confrontation and damages containment, followed by the phase of preparation and precaution, then recovery phase, and strategic learning phase), while the lowest level of implementing is associated with the phase of early warning signals detection. This result indicates that the joining operating rooms focus on impliminting some security crisis management stages and neglect others. However, the availability of such levels of implementation greatly helps to track of all security crisis management stages, and to remove obstacles that prevent the full implementation of these stages.

\section{Third: Results of hypothesis testing}

Regression analysis has been used to test study hypotheses, it

\begin{tabular}{|c|c|c|c|c|c|c|c|c|}
\hline No. & Knowledge management processes & Mean & $\begin{array}{c}\text { Std. } \\
\text { deviation }\end{array}$ & Interest rate $\%$ & T-test value & $\begin{array}{l}(\mathrm{Sig})(\mathrm{P}) \\
\text { value }\end{array}$ & $\begin{array}{c}\text { Sort by } \\
\text { importance }\end{array}$ & Approval degree \\
\hline 1 & Knowledge diagnosis & 3.88 & 0.531 & $77.6 \%$ & *28.75 & 0,000 & 4 & High \\
\hline 2 & Knowledge generating & 3.92 & 0.702 & $78.4 \%$ & *22.77 & 0,000 & 3 & High \\
\hline 3 & Knowledge storage & 4.11 & 0.518 & $82.2 \%$ & *37.25 & 0,000 & 1 & High \\
\hline 4 & Knowledge distribution & 3.97 & 0.595 & $79.4 \%$ & *28.29 & 0,000 & 2 & High \\
\hline 5 & Knowledge implementation & 3.76 & 0.639 & $75.2 \%$ & *20.66 & 0,000 & 5 & High \\
\hline \multicolumn{2}{|r|}{ All knowledge management processes } & 3.92 & 0.516 & $78.4 \%$ & *31.24 & 0,000 & - & High \\
\hline
\end{tabular}

Table 4: Analysing knowledge management processes.

\begin{tabular}{|c|c|c|c|c|c|c|c|c|}
\hline No. & Security crisis management stages & Mean & $\begin{array}{c}\text { Std. } \\
\text { deviation }\end{array}$ & $\begin{array}{c}\text { Interestrate } \\
\%\end{array}$ & T-test value & $\begin{array}{l}(\mathrm{Sig})(\mathrm{P}) \\
\text { value }\end{array}$ & $\begin{array}{c}\text { Sort by } \\
\text { importance }\end{array}$ & $\begin{array}{c}\text { Approval } \\
\text { degree }\end{array}$ \\
\hline 1 & The phase of early warning signals detection & 3.58 & 0.837 & $71.6 \%$ & *12.06 & 0,000 & 5 & High \\
\hline 2 & The phase of preparation s and precaution & 3.92 & 0.494 & $78.4 \%$ & *32.39 & 0,000 & 2 & High \\
\hline 3 & The phase of confrontation and damages containment & 3.96 & 0.399 & $79.2 \%$ & *41.92 & 0,000 & 1 & High \\
\hline 4 & Recovery phase & 3.87 & 0.479 & $77.4 \%$ & *31.60 & 0,000 & 3 & High \\
\hline 5 & Strategic learning phase & 3.81 & 0.753 & $76.2 \%$ & *18.85 & 0,000 & 4 & High \\
\hline \multicolumn{2}{|r|}{ All security crisis management stages } & 3.83 & 0.519 & $76.6 \%$ & *27.84 & 0,000 & - & High \\
\hline
\end{tabular}

Table 5: Analysing security crisis management stages. 
Citation: Abuzyead ZAM, Sherif SF (2017) The Impact of the Implementation the Concept of Knowledge Management on Security Crisis Management. Review Pub Administration Manag 5: 216. doi:10.4172/2315-7844.1000216

Page 9 of 15

has been relying on (Beta) factors, and $(\mathrm{T})$ values to determine the significance of regression equation impact. Decision rule for accepting the null hypothesis is: if the value of the calculated (T) less (when its value is positive) or greater than (when it's value is negative) its tabular value ( \pm 1.97$)$, when the confidence level (95\%) and freedom degrees (298). Also, null hypothesis can be accepted if the calculated (p) value is greater than $(0.05)$.

Before start applying regression analysis to test the study hypotheses, the scholar conducted some tests, in order to ensure the suitability of data for regression analysis assumptions, as the following: Assuming that there is no high correlation between the independent variables (multi-colinearity), the scholar used the Variance Inflation Factor (VIF) and (tolerance) test for each independent variable, taking into consideration that the (vif) dosent exceed the value (10), and (tolerance) value should be larger than (0.05). It was also ensured that the data follow the normal distribution by calculating skewness. The data follow the normal distribution, when the skewness value is less than (1). Table 6 shows the results of these tests: -

Table 6 shows that the (VIF) values for all dimensions are less than (10), ranging between (1.799-4.427). Tolerance values ranged between (0.266-0.556) which is greater than (0.05). It indicates that there is no high correlation between the independent variables can lead to misleading results for regression analysis. It was also confirmed that the data follow normal distribution where the values of the skewness coefficient were less than (1) therefore, it is possible to say that there is no real problem with the natural distribution of the study data (Table 7)

${ }^{*}$ When $(\alpha \leq 0.05)$, there is significance level.

The results in Table 7 indicate the validity of the model to test the hypotheses of the study because the calculated $(\mathrm{F})$ value is high comparing with tabular (F) value when $(\alpha \leq 0.05)$. Knowledge management processes explain (74.4\%) of variance in total dependent variable (security crisis management stages), this means that (74.4\%) of the variances in the security crisis management stages are explained by knowledge management processes. The rest of the variances is due to random variables that can not be controlled, or can not be included in

\begin{tabular}{|c|c|c|c|}
\hline $\begin{array}{l}\text { Independent } \\
\text { variables }\end{array}$ & $\begin{array}{l}\text { Variance Inflation Factor } \\
\text { (VIF) }\end{array}$ & Tolerance & Skewness \\
\hline Knowledge diagnosis & 1.799 & 0.556 & 0.634 \\
\hline Knowledge generating & 3.785 & 0.264 & 0.652 \\
\hline Knowledge storage & 3.503 & 0.285 & 0.132 \\
\hline Knowledge distribution & 3.624 & 0.276 & 0.496 \\
\hline $\begin{array}{c}\text { Knowledge } \\
\text { implementation }\end{array}$ & 4.427 & 0.226 & 0.290 \\
\hline
\end{tabular}

Table 6: The test of variance inflation factor, tolerance and skewness. the model. However, they reflect the stability of study modal, and they explain $(65.2 \%)$ of the variation in the phase of early warning signals detection. Also, they explain (61.2\%) of the variation in the phase of preparation and precaution, (39.4\%) of the variation in the phase of confrontation and damages containment, $(57.5 \%)$ of the variation in recovery phase, and (61.5\%) of the variation in the strategic learning phase. This indicates that there is a statistically significant impact of knowledge management processes in the interpretation of security crisis stages. Based on the stability of the model we can test the study hypotheses, as the following:

\section{The main hypothesis}

There is no significant effect with statistical significance at the level of indication $(\alpha \leq 0.05)$ for knowledge management process (knowledge diagnosis, knowledge generation, knowledge storage, knowledge distribution, and knowledge implementation) on the stages of managing security crises in Joint operating rooms of the Palestinian security forces.

\section{* When $(\alpha \leq 0.05)$, there is significance level}

Results of Beta and T-test values in Table 8 show that knowledge management processes (knowledge diagnosis, knowledge generation, knowledge storage, knowledge distribution, knowledge implementation) have statistically significant impact on security crisis management stages, in terms of the beta coefficients of these processes. Also, the calculated $(\mathrm{T})$ value is larger than its tabular value (1.97) when $(\alpha \leq 0.05),(P)$ is less than (0.05).

According to decision rule, we reject the null hypothesis (Ho), and accept the alternative hypothesis (Ha). This means, when ( $\alpha \leq$ 0.05 ) there is a significance level for knowledge management processes (knowledge diagnosis, knowledge generation, knowledge storage, knowledge implementation) on security crisis management stages in the joint operating rooms of the Palestinian security forces.

\section{The following sub-hypothesis stems from the main hy- pothesis}

First Sub-hypothesis: There is no significant effect with statistical significance at the level of indication $(\alpha \leq 0.05)$ for knowledge management process (knowledge diagnosis, knowledge generation, knowledge storage, knowledge distribution, and knowledge implementation) on the stage ofearly detection of early warning signals as a stage of security crisis management.

* When $(\alpha \leq 0.05)$, there is significance level

Results of Beta and T-test values in Table 9 show that that

\begin{tabular}{|c|c|c|c|c|c|c|c|}
\hline Hypothesis number & Variable dependent & Model & $\mathbf{R}^{2}$ & Sum of squares & Mean squares & Calculated (F) value & (F) sig. level \\
\hline \multirow{2}{*}{ The main hypothesis } & \multirow{2}{*}{$\begin{array}{l}\text { Security crisis management } \\
\text { stages }\end{array}$} & Regression & \multirow{2}{*}{0.744} & 60.647 & 12.129 & \multirow{2}{*}{$173.49^{*}$} & \multirow{2}{*}{0.000} \\
\hline & & Error & & 20.834 & 0.070 & & \\
\hline \multirow{2}{*}{ The first hypothesis } & \multirow{2}{*}{$\begin{array}{l}\text { The phase of early warning } \\
\text { signals detection }\end{array}$} & Regression & \multirow{2}{*}{0.652} & 138.501 & 27,700 & \multirow{2}{*}{$111.56^{*}$} & \multirow{2}{*}{0.000} \\
\hline & & Error & & 73.990 & 0.248 & & \\
\hline \multirow{2}{*}{$\begin{array}{l}\text { The second } \\
\text { hypothesis }\end{array}$} & \multirow{2}{*}{$\begin{array}{c}\text { The phase of preparations and } \\
\text { precaution }\end{array}$} & Regression & \multirow{2}{*}{0.612} & 45.271 & 9.054 & \multirow{2}{*}{$94.00^{*}$} & \multirow{2}{*}{0.000} \\
\hline & & Error & & 28.704 & 0.096 & & \\
\hline \multirow{2}{*}{ The third hypothesis } & \multirow{2}{*}{$\begin{array}{c}\text { The phase of confrontation and } \\
\text { damages containment }\end{array}$} & Regression & \multirow{2}{*}{0.394} & 19.024 & 3.805 & \multirow{2}{*}{$38.715^{*}$} & \multirow{2}{*}{0.000} \\
\hline & & Error & & 29.287 & 0.098 & & \\
\hline \multirow{2}{*}{$\begin{array}{l}\text { The fourth } \\
\text { hypothesis }\end{array}$} & \multirow{2}{*}{ Recovery phase } & Regression & \multirow{2}{*}{0.575} & 40.024 & 8.005 & \multirow{2}{*}{$80.736^{*}$} & \multirow{2}{*}{0.000} \\
\hline & & Error & & 29.546 & 0.099 & & \\
\hline \multirow{2}{*}{ The fifth hypothesis } & \multirow{2}{*}{ Strategic learning phase } & Regression & \multirow{2}{*}{0.615} & 105.788 & 21.158 & \multirow{2}{*}{$95.201^{*}$} & \multirow{2}{*}{0.000} \\
\hline & & Error & & 66.228 & 0.222 & & \\
\hline
\end{tabular}

Table 7: Results of variance analysing to make sure of the model validity to test study hypotheses. 
Citation: Abuzyead ZAM, Sherif SF (2017) The Impact of the Implementation the Concept of Knowledge Management on Security Crisis Management. Review Pub Administration Manag 5: 216. doi:10.4172/2315-7844.1000216

\begin{tabular}{|c|c|c|c|c|c|c|}
\hline Knowledge management processes & B & Std. Error & Beta & Calculated $\mathrm{T}$ value & (T) significan ce level & Null hypothesis results $(\mathrm{Ho})$ \\
\hline Knowledge diagnosis & 0.159 & 0.038 & 0.162 & $* 4.135$ & 0.000 & Rejected (there is an impact) \\
\hline Knowledge generating & 0.203 & 0.042 & 0.274 & *4.810 & 0.000 & Rejected (there is an impact) \\
\hline Knowledge storage & -0.180 & 0.055 & -0.180 & *-3.285 & 0.001 & Rejected (there is an impact) \\
\hline Knowledge distribution & 0.226 & 0.049 & 0.259 & * 4.651 & 0.000 & Rejected (there is an impact) \\
\hline Knowledge implementation & 0.358 & 0.050 & 0.441 & ${ }^{\star} 7.151$ & 0.000 & Rejected (there is an impact) \\
\hline
\end{tabular}

Table 8: Results of multiple regression analysis to test knowledge management processe's impact on the stage of managing security crises in the joint operating rooms of the Palestinian security forces.

\begin{tabular}{|c|c|c|c|c|c|c|}
\hline Knowledge management processes & B & Std. Erro & Beta & Calculated T value & (T) significance level & Null hypothesis results (Ho) \\
\hline Knowledge diagnosis & 0.330 & 0.072 & 0.209 & ${ }^{*} 4.562$ & 0.000 & 0.000 \\
\hline Knowledge generating & 0.314 & 0.079 & 0.263 & ${ }^{*} 3.951$ & Rejected (there is an impact) \\
\hline Knowledge storage & - & 0.103 & - & ${ }^{*} 3.436-$ & Rejected (there is an impact) \\
\hline Knowledge distribution & 0.286 & 0.092 & 0.203 & ${ }^{*} 3.123$ & 0.001 \\
\hline Knowledge implementation & 0.583 & 0.094 & 0.444 & ${ }^{*} 6.178$ & 0.002 & Rejected (there is an impact) \\
\hline
\end{tabular}

Table 9: Multiple regression analysis results to test the impact of knowledge management processes on the phase of early warning signals detection, as a stage of security crisis management.

\begin{tabular}{|c|c|c|c|c|c|c|}
\hline Knowledge management processes & B & Std. Error & Beta & Calculated T value & (T) significance level & Null hypothesis results (Ho) \\
\hline Knowledge diagnosis & -0.037 & 0.045 & -0.039 & ${ }^{* *}-0.813$ & 0.417 \\
\hline Knowledge generating & 0.297 & 0.049 & 0.422 & ${ }^{*} 6.011$ & 0.000 \\
\hline Knowledge storage & -0.046 & 0.064 & -0.048 & ${ }^{* *}-0.712$ & Accepted (no impact) \\
\hline Knowledge distribution & -0.009 & 0.057 & -0.011 & ${ }^{* *}-0.157$ & 0.477 \\
\hline Knowledge implementation & 0.360 & 0.059 & 0.465 & ${ }^{*} 6.127$ & Accepted (no impact) & 0.875 \\
\hline
\end{tabular}

Table 10: Multiple regression analysis results to assess the impact of knowledge management processes on the phase of preparation and precaution, as a stage of security crisis management.

\begin{tabular}{|c|c|c|c|c|c|c|}
\hline Knowledge management processes & B & Std. Error & Beta & Calculated T value & (T) significance level & Null hypothesis results (Ho) \\
\hline Knowledge diagnosis & 0.005 & 0.045 & 0.006 & ${ }^{* *} 0.105$ & 0.916 \\
\hline Knowledge generating & 0.160 & 0.050 & 0.281 & ${ }^{*} 3.204$ & 0.002 \\
\hline Knowledge storage & 0.046 & 0.065 & 0.060 & ${ }^{* *} 0.708$ & 0.479 \\
\hline Knowledge distribution & 0.104 & 0.058 & 0.155 & ${ }^{* *} 1.809$ & 0.071 \\
\hline Knowledge implementation & 0.113 & 0.059 & 0.181 & ${ }^{* *} 1.903$ & Accepted (no impact) & 0.058 \\
\hline
\end{tabular}

Table 11: Multiple regression analysis results to test the impact of knowledge management processes on the phase of confrontation and damages containment, as a stage of security crisis management.

knowledge management processes (knowledge diagnosis, knowledge generation, knowledge storage, knowledge distribution, knowledge implementation) have statistically significant impact on the phase of early warning signals detection as a stage of the security crisis management, in terms of calculated $(\mathrm{T})$ value is larger than its tabular value (1.97) when $(\alpha \leq 0.05)$, and $(P)$ is less than (0.05). Also in terms of influence statistically for beta transactions for these operations as shown in the Table.

Based ongoing of decision rule, we reject the null hypothesis (Ho), and accept the alternative hypothesis $(\mathrm{Ha})$. This mean, when $(\alpha \leq 0.05)$ there is a significant statistical significance for knowledge management processes (knowledge diagnosis, knowledge generation, knowledge storage, knowledge implementation) on the phase of early warning signals detection as a stage of security crisis management in the joint operating rooms of the Palestinian security forces.

Second Sub-hypothesis: There is no significant effect with statistical significance at the level of indication $(\alpha \leq 0.05)$ for knowledge management process (knowledge diagnosis, knowledge generation, knowledge storage, knowledge distribution, and knowledge implementation) on the stage of preparedness and prevention as a stage of security crisis management.

${ }^{*}$ When $(\alpha \leq 0.05)$, there is significance level, ${ }^{*}$ When $(\alpha \leq 0.05)$ there isn't significance level
Results of Beta and T-test values in Table 10 show that knowledge management processes (knowledge generation, knowledge implementation) are the most affecting processes on preparation and precaution phase. In terms of the calculated (T) values of those two processes $(6.127,6.011)$ are larger than tabular $(\mathrm{T})$ value $(1.97)$ when $(\alpha \leq 0.05)$, and $(P=0.000)$ which is less than (0.05). Also in terms of influence of (Beta) transactions for those proccess $(0.465,0.422)$. The results also indicate that knowledge management processes (knowledge diagnosis, knowledge storage, knowledge distribution) have no impact on the phase of preparation and precaution, in terms of the (Beta) coefficients of those processes $(-0.011,-0.048,-0.039)$. The calculated (T) values $(-0.157,-0.712,-0.813)$ were low, so, there isn't significance level of $(T)$ calculated values when $(\alpha \leq 0.05)$.

Based ongoing decision rule, we reject the null hypothesis (Ho) and accept the alternative hypothesis (Ha). This means, when $(\alpha \leq$ $0.05)$ there is significance level of knowledge management processes (knowledge diagnosis, knowledge generation, knowledge storage, knowledge implementation) on the phase of preparation and precaution as a stage of security crisis management in the joint operating rooms of the Palestinian security forces.

Third Sub-hypothesis: There is no significant effect with statistical significance at the level of indication $(\alpha \leq 0.05)$ for knowledge management process (knowledge diagnosis, knowledge generation, knowledge storage, knowledge distribution, and knowledge 
Citation: Abuzyead ZAM, Sherif SF (2017) The Impact of the Implementation the Concept of Knowledge Management on Security Crisis Management. Review Pub Administration Manag 5: 216. doi:10.4172/2315-7844.1000216

implementation) on the stage of confrontation and containment of damages as a stage of security crisis management.

${ }^{*}$ When $(\alpha \leq 0.05)$, there is significance level, ${ }^{* *}$ When $(\alpha \leq 0.05)$ there isn't significance level

Results of Beta and T-test values in Table 11 show that the knowledge generation process is the most knowledge management processes affecting the phase of confrontation and damages containment. In terms of the calculated $(\mathrm{T})$ value $(3.204)$ is larger than its tabular value (1.97) when $(\alpha \leq 0.05),(P=0.002)$ which is less than $(0.05)$. Also, the influence of (Beta) transactions for this proccess $(0.281)$. The results indicate that knowledge management processes (knowledge diagnosis, knowledge storage, knowledge distribution, knowledge implementation) have no impact on the phase of confrontation and damages containment. We can conclude that from (Beta) coefficients of these processes, and from the calculated $(\mathrm{T})$ values which are smaller than its tabular values when $(\alpha \leq 0.05)$.

Based ongoing decision rule, we reject the null hypothesis (Ho), and accept the alternative hypothesis (Ha). This mean, when $(\alpha \leq$ $0.05)$ there is a significance level of knowledge generation on the phase of confrontation and damages containment. It means also, when $(\alpha \leq 0.05)$ there isn't significance level of knowledge management processes (knowledge diagnosis, knowledge storage, knowledge implementation, know distribution) on the phase confrontation and damages containment as a stage of security crisis management in the joint operating rooms of the Palestinian security forces.

Fourth Sub-hypothesis: There is no significant effect with statistical significance at the level of indication $(\alpha \leq 0.05)$ for knowledge management process (knowledge diagnosis, knowledge generation, knowledge storage, knowledge distribution, and knowledge implementation) on the stage of restoring activity as a stage of security crisis management.

${ }^{*}$ When $(\alpha \leq 0.05)$, there is significance level, ${ }^{*}$ When $(\alpha \leq 0.05)$ there isn't significance level

Results of Beta and T-test values in Table 12 show that knowledge management processes (knowledge diagnosis, knowledge distribution, knowledge implementation) have the most significant impact on recovery phase. In terms of calculated $(\mathrm{T})$ value $(4.688,5.194,3.758)$ are larger than its tabular value (1.97) when $(\alpha \leq 0.05)$, and $(\mathrm{P}=0.000)$ which is smaller than (0.05). We can conclude from (Beta) coefficients of these processes $(0.034,0.063)$, and from the calculated $(\mathrm{T})$ values $(0.887,0.462)$ which are smaller than its tabular values when $(\alpha \leq 0.05)$.
Based ongoing of decision rule, we reject the null hypothesis (Ho), and accept the alternative hypothesis (Ha). This means, when $(\alpha \leq$ $0.05)$ there is significance level of knowledge management processes (knowledge diagnosis, knowledge implementation, know distribution) on recovery phase, and it means, if it is focused on the recovery phase it will be improved. It means also, when $(\alpha \leq 0.05)$ there is no significance level of knowledge management processes (knowledge generation, knowledge storage) on recovery phase as a stage of security crisis management in the joint operating rooms of the Palestinian security forces.

Fifth sub-hypothesis: There is no significant effect with statistical significance at the level of indication $(\alpha \leq 0.05)$ for knowledge management process (knowledge diagnosis, knowledge generation, knowledge storage, knowledge distribution, and knowledge implementation) on the stages of strategic learning phase as a stage of security crisis management.

\section{* When $(\alpha \leq 0.05)$, there is significance level}

Results of Beta and T-test values in Table 13 show that knowledge management processes (knowledge diagnosis, knowledge generation, knowledge storage, knowledge distribution, knowledge implementation) have a statistically significant impact on the strategic learning phase. In terms of the calculated $(\mathrm{T})$ value is larger than its tabular value (1.97) when ( $\alpha \leq 0.05)$, (P) is less than (0.05), and also in terms of influence statistically for (Beta) transactions for these operations as shown in the Table.

According to decision rule, we reject the null hypothesis (Ho), and accept the alternative hypothesis (Ha). This means, when ( $\alpha \leq$ 0.05 ) there is a significance level of knowledge management processes (knowledge diagnosis, knowledge generating, knowledge storage, knowledge implementation, know distribution) on strategic learning phase, as a stage of security crisis management in the joint operating rooms of the Palestinian security forces.

\section{Results and Discussion}

- The results of the study showed that the joint operating rooms are generally concerned with the implementation of all knowledge management processes to a high degree. This implementation came in varying degrees and levels. The highest level of implementation of these processes was related to storing knowledge, followed by knowledge distribution, knowledge generation, diagnosis knowledge, while the lowest level of implementation was associated with applying of knowledge. This finding indicates that the joint operating rooms do

\begin{tabular}{|c|c|c|c|c|c|c|}
\hline Knowledge management processes & B & Std. Error & Beta & Calculated $\mathrm{T}$ value & (T) significance level & Null hypothesis results (Ho) \\
\hline Knowledge diagnosis & 0.214 & 0.046 & 0.237 & *4.688 & 0.000 & Rejected (there is an impact) \\
\hline Knowledge generating & 0.023 & 0.050 & 0.034 & ${ }^{* *} 0.462$ & 0.644 & Accepted (no impact) \\
\hline Knowledge storage & 0.058 & 0.065 & 0.063 & ** -0.887 & 0.376 & Accepted (no impact) \\
\hline Knowledge distribution & 0.301 & 0.058 & 0.373 & *5.194 & 0.000 & Rejected (there is an impact) \\
\hline Knowledge implementation & 0.224 & 0.060 & 0.299 & *3.758 & 0.000 & Rejected (there is an impact) \\
\hline
\end{tabular}

Table 12: Multiple regression analysis results to test the impact of knowledge management processes on recovery phase, as a stage of security crisis management.

\begin{tabular}{|c|c|c|c|c|c|c|}
\hline Knowledge management processes & B & Std. Error & Beta & Calcul ated T value & (T) significance level & Null hypothesis results (Ho) \\
\hline Knowledge diagnosis & 0.281 & 0.068 & 0.198 & ${ }^{*} 4.106$ & 0.000 & 0.004 \\
\hline Knowledge generating & 0.219 & 0.075 & 0.204 & ${ }^{*} 2.917$ & Rejected (there is an impact) \\
\hline Knowledge storage & -0.489 & 0.098 & -0.336 & ${ }^{*}-4.991$ & 0.000 \\
\hline Knowledge distribution & 0.448 & 0.087 & 0.354 & ${ }^{*} 5.173$ & 0.000 \\
\hline Knowledge implementation & 0.510 & 0.089 & 0.432 & ${ }^{*} 5.714$ & Rejected (there is an impact) \\
\hline
\end{tabular}

Table 13: Multiple regression analysis results to test the impact of knowledge management processes on strategic learning phase as a stage of security crisis management. 
not deal with the concept of knowledge management as an integrated system, but rather deal with each process separately; in other words, it focuses on the application of some processes and neglects the sequence of other knowledge management processes in terms of degree of implementation, in this sense, the application of this concept in the joint operating rooms of the study did not exceed the mental adoption of the concept, that is, the conviction of the idea only, and thus did not reach the implementation of comprehensive and good, this means the lack of actual and serious commitment to the implementation of knowledge management processes by those rooms, and the low level of awareness and awareness among some security leaders of the importance of applying knowledge management, which may be justified by the recent adoption of joint operating rooms for the knowledge management system. This result is consistent with the findings study of $\mathrm{Al}$ Kasasbh $\mathrm{W}$ [81], the study of $\mathrm{Al} \mathrm{Zogby} \mathrm{Kh}$ and $\mathrm{Al}$ Zaidi Z [82] and the study of Darwish [83].

- The results of the study indicated that the joint operating rooms are generally concerned with applying all stages of security crisis management to a high degree. However, this implementation came in varying degrees and levels. The highest level of application of these stages was related to the stage of confrontation and containment of damages. And followed by the strategic learning phase, while the lowest level of implementation was associated with the detection phase of early warning signals. This result indicates that the joint operating rooms do not deal with the phases of security crisis management as an integrated system, The stages of managing other security crises in terms of degree of implementation, but focuses on the implementation of some stages and neglects the sequence of stages of management of other security crises in terms of degree of implementation, as the stages of security crisis management follow each stage of the other system and each stage has a beginning and end can not be separated, and may be because there may overlap and the intertwining of the stages due to the political and economic instability in Palestine, which led to the almost repeated recurrence of the security crises.

- The results of the study showed a statistically significant effect at the level of $(\alpha \leq 0.05)$ for knowledge management processes (knowledge diagnosis, knowledge generation, knowledge storage, knowledge distribution, and knowledge implementation) in the stages of security crisis management in the joint operations rooms of the Palestinian security forces. Which calls for joint operations rooms to pay more attention to these operations than they do now, because they have a significant impact on the phases of security crisis management.

- The results of the study showed that there is a statistically significant effect at the level of $(\alpha \leq 0.05)$ for knowledge management processes (knowledge diagnosis, knowledge generation, knowledge storage, knowledge distribution, and knowledge implementation) on early detection of early warning signals as a stage of managing security crises in Joint operations rooms of the Palestinian security forces.

- The results of the study showed that there is a significant impact statistically significant at the level of significance $(\alpha \leq 0.05)$ for knowledge management processes (knowledge implementation, and knowledge generation) on preparedness and prevention phase, and these two processes are the most influential on the preparedness and prevention respectively stage, while the results indicated that's no significant effect statistically significant at the level of significance ( $a$ $\leq 0.05$ ) for knowledge management processes (knowledge diagnosis, knowledge storage, and knowledge distribution ) on preparedness and prevention stage as a stage of the stages of the security crisis management in the joint operations rooms of the Palestinian security forces, this calls on the joint operating rooms to focus primarily on the implementation and generation of knowledge as the most important influences on the preparation and prevention phase in the joint operating rooms under study.

- The results of the study showed that there is a statistically significant effect at the level of $(\alpha \leq 0.05)$ for the process of generating knowledge on the stage of confrontation and containment of damages. This process is considered as the most influential on the stage of confrontation and containment of damages, while the results indicated that there is no significant effect of statistical significance at the level of $(\alpha \leq 0.05)$ for process of knowledge management (Knowledge identification, knowledge storage, knowledge distribution, knowledge implementation) at the stage of confrontation and containment of damages. This calls on the joint operating rooms to pay attention primarily to the generation of knowledge as the most important influences on the confrontation phase and the containment of damage; This means That if these rooms are want to improve the confrontation and contain the damage, it is necessary to focus on the process of generating knowledge to improve the confrontation and contain the damage as a stage from security crisis management stages in the joint operating rooms of the Palestinian security forces.

- The results of the study showed that there is a statistically significant effect at the level of $(\alpha \leq 0.05)$ for knowledge management processes (knowledge implementation, knowledge distribution, knowledge diagnosis) on the recovery stage, these processes are the most effective at the stage of regaining activity, respectively. While the results indicated that there is no significant statistical significance at the level of $(\alpha \leq 0.05)$ for the processes of knowledge management (knowledge generation, knowledge storage) on the recovery phase. This calls on the joint operation rooms to pay attention in first class to the implementation, distribution and diagnosis of knowledge as the most important effects on the restoration phase, this means that if these rooms are wanted to improve their recovery phase, these operations should be focused on improving these processes to improve the recovery phase as a stage of security crisis management in the joint operation rooms of the Palestinian security forces.

- The results of the study showed that there is a significant statistical significance at the level of $(\alpha \leq 0.05)$ for knowledge management processes (knowledge diagnosis, knowledge generation, knowledge storage, knowledge distribution, and knowledge implementation) on the strategic learning stage as a stage of managing security crises in Joint operation rooms of the Palestinian security forces, which calls on the joint operations rooms to pay attention to these operations to raise the level of their strategic learning skills, so as not to repeat the security crises that have been exposed in the future.

Based on the above, these findings indicate that the joint operating rooms do not deal with knowledge management processes as an integrated system, but deal with each process separately; that is, knowledge management processes were not applied in a comprehensive and studied manner; they were formal security and administrative practices and routine technicality. This may be justified by the modernity of the joint operating rooms of the knowledge management system, however, each knowledge management process has had an impact on the management of security crises based on the fact that the phases of security crisis management (detection of early warning signals, preparedness and prevention, confrontation and containment of damage, recovery of activity, strategic learning), cannot be done without enriching them with knowledge, because knowledge is the living conclusion of information; this means that knowledge 
Citation: Abuzyead ZAM, Sherif SF (2017) The Impact of the Implementation the Concept of Knowledge Management on Security Crisis Management. Review Pub Administration Manag 5: 216. doi:10.4172/2315-7844.1000216

Page 13 of 15

management processes are the guide, but the real guide for each stage of security crisis management, there is no management of security crises witho ut knowledge, and therefore the implementation of knowledge management processes in an integrated and targeted will inevitably lead to the management of security crises efficiently and effectively. This finding is consistent with the findings of the Mahmoud [84] the study Wang and Cheng [85], the study Wang [86], Wang and Belardo [87] and Zhihong and Wang [88].

\section{Conclusion and Recommendations}

In light of the findings of the study, the following recommendations can be given:

- The need to develop a plan to establish the serious conviction and awareness of some of the senior security leaders and officers working in the joint operations rooms at all levels of security and administrative importance of the concept of knowledge management, and best practices in the field of knowledge management and its importance and programs and implementation, and without conviction, any effort at any level was Will not succeed. Therefore, this conviction must be translated into actual concrete practices, and adequate financial, human and technological resources and facilities should be provided through a clear and specific program, as the study findings show.

- The need to give greater attention to the implementation of all knowledge management processes, and focus on the most important and influential on the stages of the security crisis management operations, if joint operations rooms want to manage security crises efficiently and effectively, that this is done without neglecting other processes; any consideration to all of the concept of operations knowledge of all administrative aspects of management, operation, and security within the joint operations rooms look complementary, even though the implementation of this concept gradually, but it must be planned to end with a holistic and organized model takes into account all the ingredients that support the role of knowledge management in managing security crises efficiently and effectively.

- The results of the study showed that the process of implementation of knowledge less knowledge management processes implementation, so the joint operating rooms should pay greater attention to the process of implementation of knowledge through the knowledge of global best practices in the implementation of knowledge, and build an organizational culture based on cooperation between officers working, and adopting a management philosophy and organizational methods that support the implementation of knowledge, delegating sufficient powers to officers in joint operations rooms to enable them to apply their knowledge, conduct more training courses related to implementation of knowledge, and attract qualified human resources to work in the implementation of knowledge, which reduces the effects of security crises at the time of the occurrence and exit with the least possible damage, as shown by the results of the study.

- The results of the study showed that the detection phase of early warning signals is less implementation of the stages of security crisis management. Therefore, the researcher recommends the need to balance the security crisis management system in the joint operating rooms by increasing the interest and implementation of the detection of early warning signals, in order to align this phase with the rest of the security crisis management system. Together, these phases form the integrated perspective of security crisis management by focusing on developing advanced databases to help them identify indicators of security crises, emphasizing the need to use scientific methods and statistical models to predict with potential security crises, as the study findings show.
- The need for further research and field studies in the same subject, but with variables and methods of measurement other than that relied upon by the researcher, and other sectors except the Palestinian security sector to come up with a more comprehensive view on this subject.

\section{References}

1. Rao SM (2012) Knowledge management: Some issues and challenges for corporate excellence in the $21^{\text {st }}$ century. IOSR Journal of Business and Management 1: 1-3.

2. Laudon CK, Laudon J (2012) "Management information systems: Managing the digital firm", Prentice Education, USA. Inc, (12th edn). p. 417

3. Ghaffari H, Rafeie M, Ashtiani AC (2012) Quality open higher education via knowledge management. Journal of Basic and Applied Sci Res 2: 1787-1792.

4. Morsi T (2011) Knowledge management and its role in developing security performance. J Alfikr Alshurti 20: 192.

5. Elmutallab AM (2008) Security knowledge management. J Alfikr Alshurti 17: 4

6. Segev E (2010) Mapping knowledge into a database model. J Knowl Manage Pract 11: 1 .

7. Lee S, Kim BG, Kim H (2012) An integrated view of knowledge management for performance. J Knowl Manage 16: 183-203

8. Rasula, J, Vuksic BV, Stemberger MI (2012) The impact of knowledge management on organizational performance. Econ Bus Re 14: 149-160.

9. Zaied AN, Hussein GS, Hassan MM (2012) Role of knowledge management in enhancing organizational performance. I. J Information Eng Electron Bus 5: 27-35.

10. Chen $\mathrm{H}$, Huang $\mathrm{HL}$ (2010) User acceptance of mobile knowledge managemen learning system: Design and analysis. Edu Tech Soc 13: 70-77.

11. Seng CV, Zannes E, Pace RW (2002) The Contributions of knowledge management to workplace learning. J Work Learn 14: 138-147.

12. Lim D, Klobas J (2000) Knowledge management in small enterprise. Electron Libr 18: 420-433.

13. Al-Zogby KH, Al-Zaidi Z (2012) The Impact of management information systems on knowledge management processes from the point of view of workers in Jordanian Ministries' centers. Jordanian J Bus Admin 8: 655

14. Alyan R (2015) Knowledge management, Amman, Dar Safa for publishing and distribution, (2nd edn). pp. 210-214

15. Martins G, Descouwzoe K (2003) Don't just management crises. New Zeeland management 50:176- 179 .

16. Loomis J (2000) Knowledge management and x generation. Rough Notes 143: 24.

17. Dassi W (2012) The Role of knowledge management in achieving competitive advantage: An applied Study in Syrian Governmental Banks Al-Baheth. 11: 166.

18. Cummings T (2005) Organization theory \& design. South-Western, (8th edn): p. 98.

19. El-Mallah E, Saleh S (2012) The Role of organizational culture in supporting knowledge management processes: A study of the views of a sample of teachers at Mosul University. J Rafidain Dev 34: 187.

20. Martin G (2006) An overview of knowledge management assessment approaches, Bridgewater State College. J Am Bus 8: 246.

21. Sabherwal R, Fernandez BI (2005) An empirical study of the effect of knowledge management processes at individual group and organizational levels. Decision Sciences 34: 229.

22. Laudon K, Laudon J (2011) Management information systems, New Jersey, Pearson Prentice Hall, Inc., Upper Saddle Rive. p. 440.

23. Mtaib H, Hassouni A (2011) Knowledge management processes and thei impact on the distinguish institutional performance: An analytical study in the general company for rubber industries in Diwaniyah, Qadisiyah. J Admin Econ Sci 13: 12

24. Qandilji A (2012) Introduction to knowledge management, Amman, Dar AlMaysara for Publishing, Distribution and Printing, (3rd edn), p. 43

25. Hassan D (2015) The role of knowledge management processes in business process reengineering: A survey study of the opinions of a sample of workers in the general company for cotton industries. J Econ Sci 43: 420. 
Citation: Abuzyead ZAM, Sherif SF (2017) The Impact of the Implementation the Concept of Knowledge Management on Security Crisis Management. Review Pub Administration Manag 5: 216. doi:10.4172/2315-7844.1000216

Page 14 of 15

26. Al Salem M (2014) Organizational knowledge management, University Book House, Beirut (1stedn). p. 81

27. Al Shammari M, Al Hadrawi H (2011) Knowledge management operations and its impact on knowledge economy indicators: An analytical study of the views of a sample of digital institutions, Al-Ghari J Econ Admin Scie (AL Kufa). p. 189

28. Ling C, Nasurdin A (2010) Knowledge management effectiveness and technological innovation, mobile technologies. Knowl and Soc. 10: 13.

29. Martins G, Descouwzoe K (2003) Don't just management crises. Opere Citato. p. 182

30. Abu Fara Y, Olayan H (2010) Relations between knowledge management process and the effectiveness of NGO activities in East Jerusalem, Al-Quds Open University. J Res and Stud 18: 59

31. Abd El Rahman, Tadars I (2014) The Level of the practice of knowledge management at Al-Balqa applied university from the point of view of administrators working in middle and higher administration. J Edu Psychol Sci 15: 562

32. Al Azzawi B (2014) The role of knowledge management in organizational performance: An empirical study in a sample of industrial organizations, Baghdad College of Econ Sci University Journal 42: 254

33. Al Banna H, Al Khafaji N (2014) Organizational empowerment strategy fo enhancing the effectiveness of knowledge management processes, Amman, Dar Al Ayyam Publishing and Distribution, (1st edn). p. 85.

34. Choo C (2010) Beyond the ba: Managing enabling contexts in knowledge organizations. J Knowl Manage 14: 592-610.

35. Al Yasiri N (2014) Crisis management, Amman, Dar Saga for Publishing and distribution, (1st edn). p. 44

36. Coombs W (2011) Protecting organization reputations during a crisis: The development and application of situational crisis communication theory. Corp Repu Rev 10: 166

37. Al Shahrani S (2014) Managing security crises operations, amman, Dar AlHamed publishing and distribution; and academy for publishing and distribution, (1st edn). p. 29

38. Al Kardousi A (2008) Security crisis management: A study of the applied theory of the Sharm El-Sheikh bombings, as a model, Cairo, Library of Arts, (1st edn). p. 9

39. Al Saraa M (2013) Security crisis management. J Secur Res 55: 175.

40. Poimenidis I, Priporas V (2008) Services managers of crisis management: Attitudes and preparation, innovative marketing. 14: 38 .

41. Unlu A, Kapucu N, Sahin B (2010) Disaster and crisis management in Turkey: A need for aunified crisis management System, Disaster Prev Manag, 19: 155-174.

42. Zhihong L, Wang H (2009) Research on the enterprise crisis management system basic on knowledge demand, "WISAOG" Nanhang, P.R. China, 22-24 May: 5-9.

43. Alwan S (2012) Crisis management at the university of al Basrah: A descriptive analytical study. J Econ Admin Sci 18: 132.

44. Pol D, Garcia PO, Pena MS, Stuyft PV (2010) Public hospital management in times of crisis: Lessons learned from Cienfuegos, Cuba (1996-2008). Health Policy 96: 64-71.

45. Hill J, Nancarrow C, Wright LT (2002) Lifecycles and crisis points in SMES, a case approach. Mark Intelligence Plan 20: 361-369.

46. Person CM, Mitroff I (1993) From crisis prone to crisis to prepared: A framework for crisis management. Acad Manage Exec 7: 48-59.

47. Al Shahrani S (2014) Managing security crises operations, Opere Citato. p. 25

48. Jameel Q, Al Manzari Sh (2003) Security crisis management program, middle east for administrative and economic development (Akoman), Dubai Police Academy, Dubai. p.16

49. Khairat T (2010) The Role of expert computer systems in security crisis management: An applied study on scientific cases, Cairo, Dar Al-Nahda Al Arabiya, (2nd edn). pp.143-144

50. Al Yasiri N (2014) Crisis management, Opere Citato. pp. 51-52

51. Al Shahrani S (2014) Managing Security Crises Operations, Opere Citato. p. 22

52. Wang W (2009) Knowledge management adoption in times of crisis. Ind Manage Data Sys 109: 445-462.
53. Al Saraa M (2013) Security crisis management, Opere Citato. p. 156

54. Al Qatawneh A (2012) The Impact of crisis management system on the organizational climate in Jordanian Commercial Banks: A field study from the Directors' Perspective, Jordanian. J Bus Admin 8: 224.

55. Nour El Din A (2010) Crisis Management systems: An applied study in antiterrorism strategies, Cairo, United Arab Marketing and Supply Company, (1st edn). p. 22

56. Hill J, Nancarrow C, Wright LT (2002) Lifecycles and crisis points in SMES, a case opproach. Opere Citato. Mark Intelligenc Plan. pp. 361-369.

57. Al Masri A (2013) What is the security strategy and stages of implementation: $A$ descriptive and analytical study with implementation on the Republic of Yemen. J Al Adel. pp. 25:70

58. Zuwalef A (2015) The Success of accounting information systems and its impact on the stages of crisis management. Dirasat J Admin Sci 42: 255.

59. Al-Zoghbi M (2014) The degree of availability of crisis management elements in the directorates of education in the Governorate of Irbid from the point of view of the heads of departments. Dirasat J Edu Sci 41: 380.

60. Al-Tarawneh A, Al-Tarawneh M (2010) Crisis management in jordanian security institutions "Jordanian Public Security Directorate: A Field Study", Arab Econ Admin Sci (Lebanon) p. 118.

61. Nasr AA (2006) Security crisis management. J Alfikr Alshurti 14: 104

62. Kasasbh AI W (2015) The Impact of knowledge management on developing a culture of excellence: a field study of commercial banks operating in the city of Tabuk, Dirasat. Admin Sci 42: 531-551.

63. Al Enezi $\mathrm{J}$ (2012) The role of knowledge management in enhancing positive organizational culture led by Border Guard in Tabuk Region, Unpublished Master Thesis, Naif Arab University for Security Sciences, Riyadh.

64. Al Zogby Kh, Al Zaidi Z (2012) The Impact of management information systems on knowledge management processes from the point of view of workers in Jordanian Ministries, Opere Citato. pp. 653-691.

65. Kasim R (2010) The relationship of knowledge management practices competencies and the organizational performance of government departments in Malaysia. Inter J Human Soci Sci 5: 219-225.

66. Darwish A (2005) Knowledge management and its implementation in the field of security. J Alfikr Alshurti 14: 139-165.

67. Al Otaibi T (2014) The effectiveness of security crisis management in the Kuwaiti National Guard, Unpublished Master Thesis, Naif Arab University for Security Sciences, Riyadh. pp. 1-139

68. Pol D, Garcla OP, Pena SM, Stuyft VP (2010) Public hospital management in times of crisis, Opere Citato. 96: 64-71.

69. Unlu A, Kapucu N, Sahin B (2010) Disaster and crisis management in Turkey: a need for a unified crisis management System, Opere Citato. pp. 155-174.

70. Nasr AA (2006) Security crisis management, Opere Citato. pp. 88-125

71. Al Araji A, Zaher Y (2004) Preparedness of organizations in response to crises, field study in the general directorate of Jordanian Civil Defense. Arab J Manag 34: 53-101.

72. Mahmoud A (2012) The Impact of knowledge transfer on the future of crisis management for the organization: an analytical study of the polling of a sample of directors of Iraqi Banks, Baghdad College of Economics and Science, University Journal. 32: 229-248.

73. Zhiyang J (2012) A framework of knowledge management systems for tourism crisis management, Sciverse Science Direct, Procedia Eng 29: 138-143.

74. Wang W, Cheng Lu Y (2010) Knowledge transfer in response to organizational crises: An exploratory. 37 : 3934-3942.

75. Wang W (2009) Knowledge management adoption in times of crisis", Opere Citato. pp. 445-462.

76. Wang W, Belardo S (2009) The Role of knowledge management in achieving effective crisis management: A case Study. J Information Sci 35: 635-659.

77. Zhihong L, Wang H (2009) Research on the enterprise crisis management system basic on knowledge demand, Opere Citato. p. 6.

78. Palestinian National Security Forces (2016) Division of Organization and Administration. Unpublished data. 
Citation: Abuzyead ZAM, Sherif SF (2017) The Impact of the Implementation the Concept of Knowledge Management on Security Crisis Management. Review Pub Administration Manag 5: 216. doi:10.4172/2315-7844.1000216

79. Sekaran $U$ (2006) Research methods for business: a skill building approach, USA, John wiley \& Sons Inc. (6th edn). p. 294.

80. Hair J, Black B, Babin B, Anderson RE, Tatham RL (2006) Multivariate date analysis, New jersey, Prentice Hall, (6th edn). ISBN-9780130329295.

81. Al Kasasbh W (2015) The Impact of knowledge management on developing a culture of excellence: A field study of commercial banks operating in the city of Tabuk, Dirasat, Opere Citato. pp. 531-551.

82. Al-Zogby KH, Al-Zaidi Z (2012) The Impact of management information systems on knowledge management processes from the point of view of workers in Jordanian Ministries, Opere Citato. pp. 653-691

83. Darwish A (2005) Knowledge management and its implementation in the field of security, Opere Citato. pp. 139-165
84. Mahmoud A (2012) The impact of knowledge transfer on the future of crisis management for the organization: an analytical study of the polling of a sample of directors of Iraqi Banks, Opere Citato. pp. 229-248.

85. Wang W, Cheng Lu Y (2010) Knowledge transfer in response to organizational crises: an exploratory, Opere Citato. pp. 3934-3942.

86. Wang W (2009) Knowledge management adoption in times of crisis. Opere Citato. 109: 445-462.

87. Wang W, Belardo S (2009) The role of knowledge management in achieving cffcctivc crisis management: A case study. Opere Citato. pp. 635- 659.

88. Zhihong L, Wang $H$ (2009) Research on the enterprise crisis management system basic on knowledge demand. Opere Citato. pp. 005-009. 